The seminar of 1963 was held at the University of Saskatchewan from August 14 to 30. There was a series of Instructional Lectures, a series of Research Lectures, and a series of Colloquium Talks. The theme of the seminar was combinatorial mathematics, but the programme included other topics. Details of the se activities are to be found on the following pages:

Research Lectures ................... 152

Instructional Lectures $\ldots \ldots \ldots \ldots \ldots \ldots \ldots \ldots \ldots$

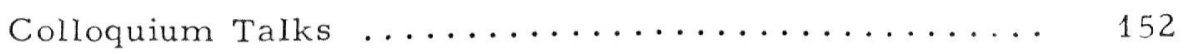

Opening Session $\ldots \ldots \ldots \ldots \ldots \ldots \ldots \ldots \ldots \ldots \ldots \ldots \ldots \ldots \ldots$

Entertainment $\ldots \ldots \ldots \ldots \ldots \ldots \ldots \ldots \ldots \ldots \ldots \ldots \ldots \ldots \ldots$

List of those attending the seminar .......... 155 
R. H. Bruck, University of Wisconsin

- Existence Problems for Classes of Finite Planes

K. Kuratowski, University of Warsaw

- Semi-Continuity in Topology

G. Pickert, University of Giessen

- Projective Planes

E. M. Wright, University of Aberdeen

- Partitions

Instructional Lectures

A. L. Dulmage, University of Manitoba

- Combinatorial Problems in Graph and Matrix Theory

A. P. Guinand, University of Saskatchewan

- Fourier Transforms and Summation Formulae

W. T. Tutte, University of Waterloo

- Graph Theory

R. G. Stanton and D. A. Sprott, University of Waterloo

- Types of Statistical Designs

\section{Colloquium Talks}

Chais:man: A. Renyi

A. Renyi,

Information theory methods in combinatorial problems.

J. Edmonds,

Sources, sinks and vortices in planar maps. 
D. R. Fulkerson,

On the maximum number of disjoint permutation matrices in a $(0,1)$ matrix.

H. J. Ryser,

On the structure of $(0,1)$ tournament matrices.

D. Sprott,

Generalizations arising from a family of difference sets.

R. C. Bose,

Partial geometries.

R. E. Greenwood,

Edge chromatic graphs and the Ramsey numbers.

R. Sandler,

Automorphisms of planar ternary rings.

M. Wells,

Computing machines and combinatorics.

R. Norman,

The Polya enumeration principle.

R. Craig,

Extensions of projective planes to uniform Hjelmslev planes.

W. Jonsson,

Projective planes of class 16.

T. Ostrom,

Projective planes with a single $(P, 1)$ transitivity. 
President Spinks of the University of Saskatchewan welcomed all participants and their wives at a formal opening session, Monday evening, August 14. Mayor Buckwold welcomed the delegates on behalf of the city of Saskatoon.

\section{Entertainment}

Members of the seminar and their wives were entertained by President and Mrs. Spinks on the evening of the opening day at the Memorial Union Building. Various other social activities were also organized by members of the Department of Mathematics at the University of Saskatchewan.

A highlight of the social activities was a one-day excursion to Prince Albert, about 80 miles north of Saskatoon, to visit the radio observatory. After this interesting visit and dinner in the local hotel, the party returned to Saskatoon by way of Batoche, the scene of the final action in the Louis Riel rebellion. While in Batoche, the members visited the old church, now a museum, which is kept in its original state, and saw the many interesting items on display there. On the return to Saskatoon, the party completed the day with a picnic at the city park. 
Artiaga, L. University of Windsor, Windsor

Baker, J.A.

Bertolini, F.

Birkinshaw, E. A.

Blum, E.

Blum, R.

Bode, Anne

Bose, R. C.

Brown, W. G.

Bruck, R. H.

Chakravartty, I. C.

Craig, R.

Crapo, H.H.

Crapo, Mrs. H.H.

Cuttle, P.

Cuttle, Mrs. P.

Dulmage, A. L.

Duncan, A.K.

Edmonds, J.

Foster, B.L.

Fulkerson, D. R.

Garner, C. W. L.

Guinand, A. P.

Greenwood, R. E.

Hall, C. D.

Hayes, J.C.

Herzberg, A. M.

Hiergeist, F.X.

Hrycay, R.

Hsu, H.

Jeffery, R. L.

Jon sson, W.J.
513 Dufferin Avenue, Saskatoon

University of Pittsburgh, Pittsburgh

Brandon College, Brandon

Acadia University, Wolfville, N.S.

University of Saskatchewan, Saskatoon

University of Western Ontario, London

University of North Carolina, Chapel Hill

University of British Columbia, Vancouver

University of Wisconsin, Madison

University of Saskatchewan, Saskatoon

Fordham University, Bronx

Northeastern University, Boston

Radcliffe College, Boston

University of Saskatchewan, Saskatoon

University of Saskatchewan, Saskatoon

University of Manitoba, Winnipeg

University of Toronto, Toronto

National Bureau of Standards, Washington

Denver Research Center, Littleton, Colo.

13125 Warren Avenue, Los Angeles

University of Toronto, Toronto

University of Saskatchewan, Saskatoon

University of Texas, Austin

University of Saskatchewan, Saskatoon

College Militaire Royal, St. Jean, P.Q.

University of Saskatchewan, Saskatoon

University of Pittsburgh, Pittsburgh

713 Temperance Street, Saskatoon

University of Saskatchewan, Saskatoon

Acadia University, Wolfville, N.S.

University of Manitoba: Wimipeg 
Kalbfle isch, J.G.

Kelly, J.B.

Kuratowski, K.

Langerholc, J.

MacNeill, I. B.

Malik, M.A.

Martin, J.R.

Melter, $R$.

Mendelsohn, N.S.

Miller, C.E.

Moser, W.

Moser, L.

Mullin, R.

Murdeshwar, M.

Nasim, C.

Norman, R.

O'Connor, R. Eric

Ostrom, T.G.

Pearson, T. L.

Pickert, G.

Pullman, N.J.

Renyi, A.

Ritcey, L. F.S.

Robinson, G. de B.

Rohatgi, V.K.

Roth, R. L.

Ryser, H.J.

Sandler, $R$.

Saucier, J.

Seiden, E.

Sherk, F.A.

Shklov, N.

Smith, R. A.

Sprague, R. H.

Sprott, D. A.
University of Waterloo, Waterloo, Ontario

Arizona State University, Phoenix

University of Warsaw, Warsaw, Poland

University of Pittsburgh, Pittsburgh

Ste 15, Braemar Apts., Saskatoon

2442 Maplewood, Montreal

1314 Osler Street, Saskatoon

University of Rhode Island, Kingston

University of Manitoba, Winnipeg

University of Saskatchewan, Saskatoon

University of Manitoba, Winnipeg

University of Alberta, Edmonton

14 Lonsdale Drive, Guelph, Ontario

University of Alberta, Edmonton

University of Saskatchewan, Saskatoon

Dartmouth College, Hanover, N. H.

Loyola College, Montreal

Washington State University, Pullman

1122 - 13th St. E., Saskatoon

University of Giessen, Germany

McGill University, Montreal

University of Budapest, Hungary

Canadian Mathematical Congress, Montreal

University of Toronto, Toronto

University of Alberta, Edmonton

University of Colorado, Boulder

Syracuse University, Syracuse, N. Y.

202 Linden Lane, Princeton, N.J.

226 St. George St., Toronto

Michigan State University, E. Lansing

University of Toronto, Toronto

University of Saskatchewan, Saskatoon

Pennsylvania State University,

State College, Penn.

lowa State University, Ames

University of Waterloo, Waterloo, Ontario 
Stanton, R. G.

Sudler (Jr.), C.

Thomas, G.

Tingley, A.J.

Tutte, W. T.

Upadhyay, M. D.

Wahab, J.H.

Wells, M. B.

Williams, W. L. G.

Wright, E. M.

Younger, D. H.

Zeiler, F.
University of Waterloo, Waterloo, Ontario 1025 2nd Street, Santa Monica, California

University of Saskatchewan, Saskatoon

Dalhousie University, Halifax, N.S.

University of Waterloo, Waterloo, Ontario

University of Saskatchewan, Saskatoon

Charlotte College, Charlotte, N.C.

190 Manhattan Loop, Los Alamos, N. M.

Canadian Mathematical Congress, Montreal

University of Aberdeen, Scotland

Princeton University, New Jersey

University of Manitoba, Winnipeg 
158

https://doi.org/10.1017/S0008439500024619 Published online by Cambridge University Press 